
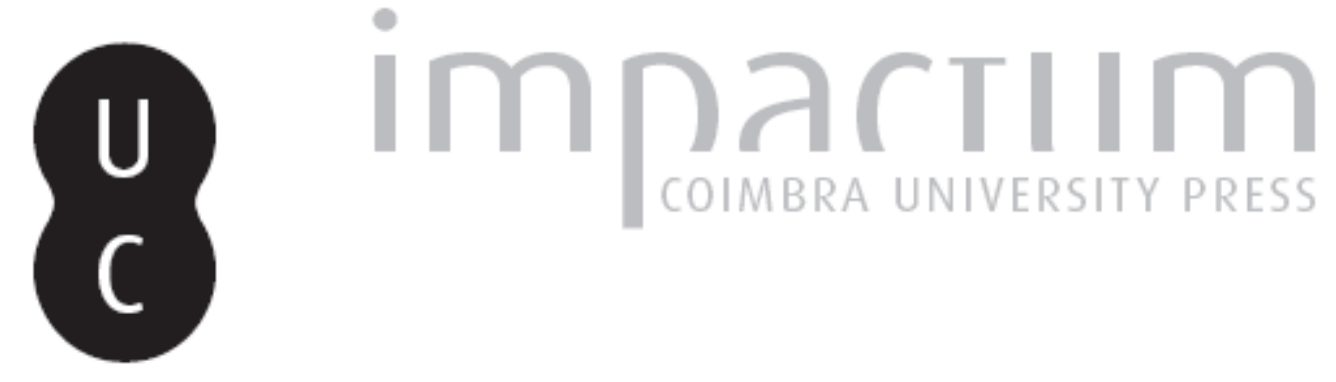

[Recensão a] Rodrigues, Ana Maria S.A., Silva, Manuela Santos e Faria, Ana Leal de coords. (2017). Casamentos da Família Real Portuguesa. Diplomacia e cerimonial
Autor(es):
Casanova, Covadonga Valdaliso

Publicado por: Imprensa da Universidade de Coimbra

URL persistente:

URI:http://hdl.handle.net/10316.2/43345

DOI:

DOI:https://doi.org/10.14195/1645-2259_17_20

Accessed : $\quad$ 26-Apr-2023 08:49:43

A navegação consulta e descarregamento dos títulos inseridos nas Bibliotecas Digitais UC Digitalis, UC Pombalina e UC Impactum, pressupõem a aceitação plena e sem reservas dos Termos e Condições de Uso destas Bibliotecas Digitais, disponíveis em https://digitalis.uc.pt/pt-pt/termos.

Conforme exposto nos referidos Termos e Condições de Uso, o descarregamento de títulos de acesso restrito requer uma licença válida de autorização devendo o utilizador aceder ao(s) documento(s) a partir de um endereço de IP da instituição detentora da supramencionada licença.

Ao utilizador é apenas permitido o descarregamento para uso pessoal, pelo que o emprego do(s) título(s) descarregado(s) para outro fim, designadamente comercial, carece de autorização do respetivo autor ou editor da obra.

Na medida em que todas as obras da UC Digitalis se encontram protegidas pelo Código do Direito de Autor e Direitos Conexos e demais legislação aplicável, toda a cópia, parcial ou total, deste documento, nos casos em que é legalmente admitida, deverá conter ou fazer-se acompanhar por este aviso.

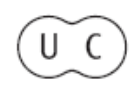




\section{Rodrigues, Ana Maria S.A., Silva, Manuela Santos e Faria, Ana Leal de coords. (2017). Casamentos da Família Real Por- tuguesa. Diplomacia e cerimonial. Lisboa: Círculo de Leitores. ISBN: 978-972-42-5129-5}

Do ponto de vista teórico, a divulgação histórica deveria ser o canal através do qual a evolução da investigação académica seria transmitida a todos aqueles que, em maior ou menor medida, se encontram distanciados das universidades e dos centros de investigação. Na prática, esse canal é controlado por editores e profissionais da comunicação, muitos dos quais nem sempre estão familiarizados com essa investigação, mas, em alternativa, consideram-se bons conhecedores daquilo que "o público" (os leitores, os ouvintes, os espectadores) "quer" (ler, ouvir ou ver). Inverte-se assim o processo e a divulgação (ato ou efeito de divulgar, de tornar conhecido do público, de publicar), que em vez de ser uma atividade de disseminação do conhecimento, acaba por ser um exercício - raramente lucrativo - onde os autores, previamente convidados ou convocados, têm de responder a determinadas perguntas. Geralmente importa pouco se essas perguntas fazem algum sentido do ponto de vista de um especialista, se através delas são colocadas questões de interesse ou se o que se procura tem relação com as investigações em curso.

Esta realidade condiciona muito o trabalho dos historiadores, porque limita as vias de comunicação com a sociedade e porque, ao fazê-lo, acaba por isola-los em espaços confinados, onde o diálogo é apenas entre pares. Também limita as suas tarefas e impede que existam perspetivas laborais alternativas, quer para eles, quer para as pessoas por eles formadas. Em consequência, faz deles uma comunidade sustentada quase exclusivamente com fundos públicos, que a sociedade nem sempre compreende e, muitas das vezes, considera inútil e obsoleta. No âmbito da edição, esta situação torna-se um problema especialmente grave. Dado que o historiador não pode mostrar o resultado das suas investigações sob a forma de um novo medicamento, um objeto ou um avanço tecnológico, porque a sua ferramenta - de trabalho e de comunicação - é a escrita, quando essa escrita é obrigada a responder àquilo que um editor considera que é divulgação, a maior parte das vezes não é apenas preciso adapta-la mas também submete-la a coordenadas, temáticas e formas que acabam por transformar o que o autor poderia - e gostaria de - transmitir, num discurso completamente diferente.

Neste contexto, prejudicial não só para o "grémio dos historiadores" mas também para a sociedade da qual fazem parte, há notáveis exceções; e as iniciativas do Círculo de Leitores são um bom exemplo. Com as coleções de biografias 
de reis e rainhas, a editora mostrou que é possível "libertar" os especialistas dos constrangimentos impostos e, no entanto, publicar textos acessíveis e de interesse para um conjunto de leitores amplo e não definido. Textos que são, aliás, um contributo para o âmbito científico e um exercício de autorreflexão historiográfica. A monarquia permitia delimitar uma cronologia concreta, que abrangia e determinava um período, simultaneamente vasto e delimitado, da história portuguesa. Possibilitava, aliás, revisitar essa história desde uma perspetiva - aquela que caracteriza o discurso histórico mais tradicional, a da história "historizante" oitocentista - mais reconhecível para as pessoas não relacionadas com a investigação histórica. Paralelamente, para os autores, a temática servia de pretexto para refletirem sobre as suas próprias perspetivas, a sua relação com o passado que estudam, a sua maneira de observa-lo, analisa-lo e descreve-lo.

Através desta nova publicação, Casamentos da Família Real Portuguesa. Diplomacia e cerimonial, o Círculo de Leitores reforçou, e dalguma maneira 'casou' simbolicamente, as duas coleções anteriores. A obra, dividida em dois volumes de mais de quatrocentas páginas cada um, com um total de vinte artigos e dezassete autores, desenvolve um único discurso, que é sintetizado nas páginas introdutórias. Fala-se nelas de como, até agora, não existia "nenhum estudo de conjunto sobre os casamentos da Casa Real portuguesa”, embora existissem "muitas análises sectoriais e sobretudo bons instrumentos de trabalho". A gravidade desta lacuna bibliográfica ressalta a importância do seu preenchimento. Acentue-se que analisar os casamentos é estudar a família e, em consequência, os laços, os relacionamentos, os filhos, a sucessão; e todos estes elementos são essenciais para a monarquia, que em essência é o depósito do poder numa família. Para um membro da família real, casar significava abrir uma via para possibilitar a continuidade - hoje chamada - dinástica. Paralelamente, casar era também contribuir para o fortalecimento da rede político-familiar que formava o conjunto de monarquias europeias. Por último, casar era - e ao longo da história portuguesa há vários exemplos - criar um vínculo como uma outra entidade geopolítica para manter a independência da própria.

Na sessão de lançamento deste único livro, dividido em duas partes, que decorreu na Faculdade de Letras da Universidade de Lisboa no dia 23 de fevereiro do presente ano, a singularidade da obra foi destacada. Ao longo das intervenções de Luís Miguel Duarte e de Ana Paula Avelar foi sublinhada a unicidade do texto; mas também foi assinalado como os volumes agrupam um conjunto de trabalhos variados, organizados numa ordem cronológica, que analisam aspetos muito precisos e aproximam o leitor a diversas temáticas: os estudos de género e os estudos sobre as mulheres; a história da diplomacia e a história da política externa; os estudos de corte e a análise das cerimónias; a história das emoções; a história das sepulturas; a história do que poderia ter acontecido mas 
não aconteceu. São, assim, tratados não apenas os casamentos e os elementos ligados a eles de maneira direta (negociações, embaixadas, mediações, contratos, dotes, cerimónias, festas), mas também questões que se relacionam com as uniões matrimoniais da família real e ajudam a compreender melhor a história da monarquia como instituição, bem como a história de um país que se formou como - e durante muito tempo foi - um reino.

Importa salientar que o livro é o resultado, e a materialização em papel, de um encontro científico, de duas sessões, realizado na mesma Faculdade de Letras em 2011 e 2013. Com esta publicação se mantem, portanto, aberta essa porta que permite à sociedade comunicar com o mundo científico-académico, sedeado fundamentalmente nas universidades. Trata-se de uma porta necessária, que deve permanecer aberta. $\mathrm{O}$ apoio da editora e a sua capacidade de distribuição são, neste sentido, fulcrais. Fazer chegar ao público não académico, não apenas os factos, a informação, o discurso atualizado do relato historiográfico desde a perspetiva do presente, mas também os enfoques e tendências da historiografia atual, o que se faz na academia, é positivo para os historiadores, para as editoras e para a sociedade. $\mathrm{O}$ que restaria para concretizar esse panorama ideal, e bastante utópico quando observado desde o presente, era o apoio estatal e o reconhecimento destas atividades divulgativas no âmbito científico. Infelizmente, hoje em dia, a divulgação é ainda pouco respeitada. Tudo o que se relacione com ela é valorizado na teoria, mas muito desconsiderado na prática, e tomado como de pouco peso - quando não conotado como negativo - nas avaliações dos méritos científicos. Publicações como Casamentos da Família Real Portuguesa são fundamentais para que esta situação acabe por mudar, o que irá de facto transformar o papel da historiografia atual na sociedade.

Covadonga Valdaliso Casanova CHSC - U. Coimbra / CHUL - U. Lisboa covaldaliso@gmail.com 